\title{
RETOS DEL FINANCIAMIENTO PARA LA VIVIENDA EN MÉXICO
}

\section{CHALLENGES OF HOUSING FINANCING IN MEXICO}

\author{
Salvador Garcia Espinosa ${ }^{1}$ \\ Rsalia Lopez Paniagua ${ }^{2}$ \\ Maria de la Luz Zavala Villagómez ${ }^{3}$
}

\section{Resumen}

El déficit de vivienda en México es un problema social que pese a que se ha incrementado considerablemente el número de viviendas en el país no se ha logrado reducir la enorme demanda que existe por este bien y que representa un símbolo de seguridad elemental para sus usuarios. En el presente artículo se analizan las características de la vivienda en México y el financiamiento para la vivienda a partir de datos estadísticos del INEGI demostrando que el incremento de número de viviendas sin la adecuada localización, infraestructura y calidad en los materiales, sistemas constructivos y consideraciones adicionales del entorno y el usuario no genera un desarrollo urbano adecuado, adicionalmente, la demanda que existe de vivienda no permite generar una competencia adecuada en el mercado ya que la demanda es mayor a la oferta y esto permite que las viviendas cuenten con las características antes mencionadas. Otra de las características que ha marcado el hecho de que el Estado ha dejado en los desarrolladores privados el problema de la vivienda es el hecho del crecimiento desordenado e innecesario del espacio urbano en las ciudades que en la mayoría de las ocasiones no obedece a la demanda.

Palabras clave: Financiamiento; México; Características de la Vivienda; Urbanismo; Estadística

\begin{abstract}
The housing deficit in Mexico is a social problem that, despite the fact that the number of homes in the country has increased considerably, has not been able to reduce the enormous demand that exists for this good and that represents a symbol of elementary security for its users. The present article analyzes the characteristics of housing in Mexico and financing for housing based on INEGI statistical data showing that the increase in the number of houses without adequate location, infrastructure and quality in materials, construction systems and considerations additional to the environment and the user does not generate a suitable urban development, additionally, the demand that exists of housing does not allow to generate an adequate competition in the market since the demand is greater to the offer and this allows that the houses have the characteristics before mentioned. Another characteristic that has

\footnotetext{
${ }^{1}$ Doctorado en geografía por la Universidad Autónoma de México. Profesor Investigador de la UMSNH desde el 2000 hasta la fecha en programas de licenciatura y posgrado. E-mail: salgaes1@gmail.com

${ }^{2}$ Doctora en Sociología y Filosofía. Investigadora titular en el Centro de Investigaciones Interdisciplinarias en Ciencias y Humanidades de la UNAM, y por convenio de colaboración profesora investigadora en la División de estudios de posgrado en la Facultad de Economía de la Universidad Michoacana de San Nicolás de Hidalgo. E-mail: rosalial@unam.mx

${ }^{3}$ Actualmente estudia el Doctorado en Ciencias en Desarrollo Sustentable en la Facultad de Economía de la UMSNH. Profesora de asignatura desde 2005 en la Facultad de Arquitectura de la UMSNH. E-mail: arq_zv@hotmail.com
} 
marked the fact that the State has left in private developers the problem of housing is the fact of disorderly and unnecessary growth of urban space in cities that in most cases does not obey the demand.

Keywords: Financing; Mexico; Housing Characteristics; Urbanism; Statistics

\section{INTRODUCCIÓN}

Uno de los ejes primordiales de la política social en México es la vivienda, ya que constituye un elemento fundamental del bienestar familiar al proporcionar a sus usuarios seguridad, sentido de pertenencia e identidad, además de ser un derecho constitucional (García y García, S/F:1). Bajo esta premisa, el objetivo del ambiente artificial propiciado por la vivienda es generar una calidad de vida a sus usuarios.

El presente documento realiza un análisis histórico de los sistemas de financiamiento para la vivienda y analiza las características de la vivienda y de su financiamiento en México con datos estadísticos del INEGI (Instituto Nacional de Geografía y Estadística).

Históricamente en México se han buscado los mecanismos para facilitar a los trabajadores ser poseedores de una vivienda. Es en el año de1954 que se crea la primera Ley de Condominio que genera la creación de organismos que administran y regulan la vivienda, sin embargo como se analiza dichas actuaciones no han sido suficientes para reducir la demanda de vivienda en nuestro país.

Los antecedentes de los sistemas de financiamiento de la vivienda se generan en 1865 con la Ley sobre Trabajadores que obliga a proveer de habitación y vivienda a obreros del campo, hecho que en 1947 se consolida con el Fondo de Casas Baratas. Se observa que las actuaciones en política de vivienda aunque han sufrido innumerables modificaciones no han logrado reducir el rezago de vivienda en nuestro país.

\section{PLANTEAMIENTO DEL PROBLEMA}

Las políticas de vivienda en nuestro país deben establecer y fomentar la calidad de la vivienda considerando factores como el sistema constructivo adecuado y acorde a los materiales regionales que preserven sus rasgos culturales característicos, respeto al entorno ecológico, su conservación y el uso eficiente de sus recursos, así como que respondan a un 
adecuado ordenamiento territorial acorde a la localidad, conservación de los rasgos edificados y urbanos de la evolución cronológica, y su historia (García y García, S/F:1).

A nivel internacional existen organismos que fomentan el derecho a la vivienda, tal es el caso de la Carta Mundial por el Derecho a la Ciudad (ONU HÁBITAT, 2001:94-95), que enfatiza el derecho a servicios e infraestructura como una forma de asegurar la distribución y disfrute equitativo, universal, justo, democrático y sustentable de los recursos, riquezas, servicios, bienes y oportunidades que brinda la ciudad.

Se debe contar con vivienda garante de la calidad de vida para todos, que contribuya a lograr prosperidad y sustentabilidad, conservando los recursos naturales, el uso eficiente de energías y uso de energías renovables (Alavedra, et al, 1997:41-42), que vislumbre la vivienda como parte de un entorno y parte fundamental de la ciudad, no como un elemento aislado. Para lograrlo es necesario que la vivienda con las características enumeradas sea accesible a toda la población, ya sea mediante el financiamiento o ahorro.

Sin embargo, el gran negocio inmobiliario en México cuenta con el estímulo de políticas de desregularización, privatización y liberación manifestados en los programas de vivienda vigente como medio con el que los gobiernos intentan atender la demanda social de vivienda (Isunza, 2010:2). Estas políticas no tienen como objetivo solventar las necesidades sociales de vivienda, al dejar desprotegidos a trabajadores que no cuentan con prestaciones o no son asalariados y que son los más necesitados en la adquisición de una vivienda.

Específicamente, la política financiera en vivienda ha tenido un escaso impacto en las condiciones de la vivienda de la población mayoritaria de bajos recursos, debido al limitado número de viviendas financiadas en relación a la demanda efectiva. Grandes segmentos de la población simplemente no reúnen los requisitos necesarios para constituirse como sujetos de crédito de los programas, aunado a la poca claridad que sigue imperando en torno a la cuestión de los subsidios (Connolly, 1997:52-53).

Un determinado sistema de financiamiento habitacional facilita (o no) el desarrollo de la producción de vivienda en ciertas modalidades, pero también puede facilitar u obstaculizar la producción social de la vivienda por parte de otros actores sociales del llamado "tercer sector". En México el criterio político predominante sobre el social en la distribución de los recursos y la propia ausencia del criterio financiero ha contribuido al reparto irracional de recursos crediticios escasos (Connolly, 1997:21, 52).

En nuestro país, los sistemas financieros de vivienda de captación de ahorro o "fondeo" cuentan con las siguientes fuentes: 
1. Ahorro captado por las instancias de intermediación financiera que conforman la banca y otras instituciones;

2. Contribuciones patronales a los fondos de "ahorro solidario", como el INFONAVIT (Instituto del Fondo Nacional de Vivienda de los Trabajadores) y el FOVISSSTE (Fondo de Vivienda del Instituto de Seguridad y Servicios Sociales de los Trabajadores del Estado); Y

3. Recursos fiscales mezclados con otros fondos, canalizados mediante organismos gubernamentales y bancos de fomento. Adicionalmente los préstamos del Banco Mundial (Connolly, 1997:22).

4. Sin embargo no existe claridad ni pertinencia en cómo los fondos para financiamiento y subsidio a la vivienda son empleados.

\section{OBJETIVO}

Analizar las características históricas de los tipos de financiamiento para la vivienda y las características actuales de la vivienda en el país, así como un análisis relacionado entre vivienda y financiamiento de los últimos años en México.

\section{METOdOLOGÍA}

Con el fin de analizar el sistema financiero para la vivienda se realiza un análisis histórico documental de los sistemas de financiamiento para la vivienda en nuestro país, así como un análisis actual de las cifras que con respecto a este tema cuenta el INEGI.

Los datos estadísticos del INEGI que se emplearon para el presente trabajo parten del año 1990 al 2016, específicamente aquellos relacionados con la vivienda, sus características y financiamiento que se pueden resumir en tipo de vivienda y espacios construidos; régimen de propiedad y de tenencia; características constructivas y servicios; y financiamiento.

El análisis de los aspectos relacionados con el financiamiento para la vivienda incluye:

1. Financiadoras y los montos de inversión de cada una de ellas

2. Destino del financiamiento

3. Número de financiamientos 


\section{ANÁLISIS HISTÓRICO DEL FINANCIAMIENTO PARA LA VIVIENDA EN MÉXICO}

Tras el triunfo de la revolución mexicana en México se establecen los primeros indicios de la política social nacional en la Constitución Política de los Estados Unidos Mexicanos de 1917 publicada en el Diario Oficial de la Federación que en su artículo 127 apartado XII cita:

"En toda negociación agrícola, industrial, minera o cualquiera otra clase de trabajo, los patronos estarán obligados a proporcionar a los trabajadores, habitaciones cómodas o higiénicas, por las que podrán cobrar rentas que no excederán del medio por ciento mensual del valor catastral de las fincas. Igualmente deberán establecer escuelas, enfermerías y demás servicios necesarios a la comunidad. Si las negociaciones estuvieren situadas dentro de las poblaciones, y ocuparen un número de trabajadores mayor de cien, tendrán la primera de las obligaciones mencionada" (de Diputados, 1917:159).

Sin embargo, los empleadores se amparaban de dicha responsabilidad por lo que en el año de 1970 se reglamentó de forma oficial la XII fracción del Artículo 123 en la Ley Federal del Trabajo capítulo III del título IV, denominado "Habitaciones para los trabajadores" que obliga a los patrones a proporcionar habitaciones cómodas e higiénicas a los trabajadores, sin embargo dicha obligación eximia a muchas empresas y los empleadores contaban con un medio para evitarlo, pues en el artículo 151 de la misma Ley se establecía que mientras no se hiciera entrega de las habitaciones a los trabajadores, tendrían éstos derecho a una retribución mensual (Saucedo, 2012:8).

En 1963 el Programa Financiero de Vivienda (PFV) en el marco de la Alianza para el Progreso, el Banco Interamericano del Desarrollo y la Agencia Internacional de Desarrollo mediante capital semilla generan un fondo de financiamiento de vivienda popular promovida por el recién creado FOVI (Fondo de Operación y Descuento Bancario a la Vivienda) y que además captaba $30 \%$ de las cuentas de ahorro al menudeo depositadas en banca comercial, en sustitución de una parte del encaje legal como parte de la Ley General de Instituciones de Crédito y Organismos Auxiliares (1963), sin embargo no permitió esto canalizar los ahorros de un sector con mayores recurso a otro con menores, por el contrario, se financiaron pocas viviendas para el sector medio (Connolly, 1997:28-30).

Hasta finales de 1960, el financiamiento a la vivienda era mediante la canalización de una parte de los fondos de los sistemas de seguridad social (ISSSTE e IMSS [Instituto Mexicano del Seguro Social]) que financiaba la construcción de vivienda, el otorgamiento de créditos habitacionales como salario indirecto a trabajadores sindicalizados, y las viviendas financiadas 
por BANOBRAS (Banco Nacional de Obras y Servicios Públicos S.A.), y vendidas a crédito principalmente a personas de medianos ingresos (Connolly, 1997:25-27).

En 1970, un estudio de la Comisión Nacional Tripartita en relación a las leyes de vivienda determinó dificultades por la que no se avanzaba en dicho rubro, entre las que destacan que sólo se protegía a una porción de trabajadores, las empresa no podían hacerse cargo de la exigencia y la problemática de generar una legislación para todas las empresas. Esto propició que se generara un fondo nacional de vivienda para otorgar préstamos al sector obrero para la adquisición, construcción, reparación y mejoramiento de sus habitaciones, especificando el carácter crediticio y financiero que se capitalizaría con las aportaciones de las empresas de depósitos a favor de sus empleados (Saucedo, 2012:8-9).

Se crearon los fondos de ahorro solidario para el financiamiento de la vivienda, con un aporte patronal del 5\% sobre nóminas constituidos en fondos de financiamiento habitacional (INFONAVIT, FOVISSSTE [creado el 11 de noviembre de 1972], FOVIMI [Fondo de la Vivienda Militar]) (Connolly, 1997:33-36).

El proyecto fue de tal que requería de la creación de una ley y un organismo formal integrado por representantes del Gobierno Federal, de los trabajadores y de los patrones para poder administrar los recursos del fondo nacional de vivienda. La Ley del Instituto del Fondo Nacional de la Vivienda para los Trabajadores se publica en el Diario Oficial de la Federación el 24 de abril de 1972 y se consolida con la creación del INFOVAVIT como lo establece dicha ley en el Artículo 2ㅇ (Saucedo, 2012:9).

Los financiamientos INFONAVIT beneficiaron a la población asalariada de bajos ingresos, inclusive de un solo salario mínimo que contribuyó a reducir los asentamientos irregulares, arrendamiento y el déficit cualitativo y cuantitativo de vivienda (Connolly, 1997:33-36).

A raíz de la inflación en 1982 el sistema de financiamiento de la vivienda entro en crisis. Para 1984 se diseña un esquema re refinanciamiento con el objeto de evitar la descapitalización de los activos hipotecarios y reducir el subsidio financiero, sin embargo, esto llevo a la eliminación como beneficiario potencial del programa a la población de menores recursos, aun cuando logró financiar casi un $20 \%$ de la vivienda construida en el país y duplicar la proporción de captación bancaria dedicada a la vivienda media (Connolly, 1997:30-32).

Una de las reformas menos afortunadas en lo referente a la vivienda fue la que se hizo a la Ley del INFONAVIT en el año 1992 y que permitió la apertura a créditos del organismo de cuatro salarios mínimos, perdiendo con ello su carácter social, lo que elevo la construcción de vivienda y la asignación de créditos pero no a las personas de menores recursos, produciendo 
que el sector inmobiliario creciera de manera notable (Schteingart y García, 2006:44-46). Esto favoreció a los trabajadores con mayores ingresos y propició que los contribuyentes con menores ingresos subsidiaran a los de mayores ingresos (Connolly, 1997:37).

Como antecedente de dicha modificación se tiene el Programa para el Fomento y Desregulación de la Vivienda impulsado por el Banco Mundial, cuyo principal objetivo era disminuir el papel regulador del Estado en la actividad habitacional, enmarcado por principios de la ideología neoliberal. Adicionalmente, el Banco Mundial impuso la supresión de subsidios, la restricción en el otorgamiento de crédito para la adquisición de terrenos y la simplificación de los procedimientos burocráticos, destacando la función del mercado como instancia rectora del sector favoreciendo a los desarrolladores privados (Esquivel, 2006:86-88).

El Instituto Nacional para el Desarrollo de la Comunidad Rural y de la Vivienda Popular (INDECO) sustituye al Instituto Nacional de Vivienda en 1971, tuvo un papel primordial en la constitución de reservas territoriales para la vivienda hasta 1981.

El Fondo de Habitaciones Populares (FHP, se crea 1933) financiado por BANOBRAS, cuya principal participación se centró en la Ciudad de México. Para el año de 1985 el FHP se convierte en el Fideicomiso Fondo Nacional de Habitaciones Populares (FONHAPO) con el fin de financiar la vivienda popular para personas que ganen de dos y medias veces el salario mínimo y ser no asalariadas. Esto logró descentralizar administrativa y territorialmente la administración de los créditos así como dio el primer gran impulso de la capacidad de gestión de las instituciones locales de vivienda (Connolly, 1997:38-42).

El FONHAPO impulsó la responsabilidad colectiva frente al financiamiento, tanto para el pago del "enganche", como para el pago oportuno de las mensualidades, sin embargo a falta de suelo para la vivienda sus acciones se han frenado (Connolly, 1997:43).

Entre 1992 y 1994 se incrementó espectacularmente el número de créditos a la vivienda, principalmente para nuevas. Esto es consecuencia de modificaciones en el PFV y en las operaciones de FOVI que se resumen en que la banca quedo liberada de la obligación de financiar vivienda social, el mercado de la vivienda media quedo en manos de la banca comercial, se sustituyó la captación bancaria de FOVI por recursos del Banco de México y préstamos del Banco Mundial. Adicionalmente el INFONAVIT y FOVISSSTE se reformaron radicalmente, lo que ha limitó su participación (Connolly, 1997:44-46).

Durante el 2001 se incrementaron los créditos hipotecarios ejercidos y el monto de inversión mediante cofinanciamiento que propicia la participación bancaria comercial en el financiamiento de vivienda de interés social, favoreciendo la construcción de viviendas por 
grandes desarrolladores inmobiliarios que favorecieron la fragmentación urbana (Isunza, 2010:2), hecho que se ve reflejado en el incremento del uso urbano sin ser acorde a las necesidades de crecimiento y demanda poblacional, generando la escasez de suelo urbanizable y el incremento en el precio de la vivienda, razonando sobre mercados (Naredo, 2003).

En los últimos años, el sector de vivienda en México experimentó un fuerte crecimiento en la banca comercial debido a cinco factores determinantes:

1. Estabilidad macroeconómica, debido al crecimiento económico, reducción dela inflación e incremento en el poder adquisitivo, así como estructuras viables a largo plazo.

2. Aumento de la demanda, se crearon nuevos hogares, el déficit habitacional de los segmentos asalariados, independientes, mixtos y emergentes.

3. Se generó abundante oferta crediticia (hipotecas); tasas fijas, mixtas y variables, así como atributos competitivos y un dinámico sector de la construcción de vivienda.

4. Apoyo gubernamental con reguladores eficientes y la ley de transparencia, metas agresivas, y organismos de gobierno; CONAVI, INFONAVIT, FOVISSSTE, SHF.

5. Se generó un mercado secundario que propicio las bursatilizaciones, aseguradoras de crédito, y tenedores fiduciarios (BBVA Bancomer, 2009:7).

El papel del financiamiento para la adquisición de vivienda en nuestro país es una tarea pendiente del Estado, que no debe seguir en manos del mercado.

\section{OPCIONES ACTUALES DE FINANCIAMIENTO PARA LA VIVIENDA}

El adquirir una vivienda representa una de las aportaciones más significativas al patrimonio personal, cuando no se puede adquirir de contado se puede acceder en muchos casos a un financiamiento (PROFECO, 2004:13). Las opciones que se ofrecen actualmente en nuestro país son:

1. Apoyo y financiamiento para la vivienda social: Son apoyos de Gobierno Federal para adquisición y mejoramiento de la población con menores ingresos.

a. INFONAVIT otorga financiamiento hasta por 350 veces el salario mínimo (247 mil pesos) y un plazo hasta por 30 años cuya tasa de interés fluctúa entre el 3\% y 9\% (Datos al año 2004). Se debe ser trabajador cotizando con el IMSS. Es un órgano tripartito.

b. FONHAPO otorga créditos para la adquisición de vivienda social nueva programados por IOS OREVIS (Organismos Estatales de Vivienda) a familias hasta por cuatro veces el salario mínimo mensual del D.F. amortización de 30 años y una tasa de interés de $4 \%$ 
anual sobre saldos insolutos. Se deben cubrir seguros de vida, escrituración y un enganche de 500 veces el salario estipulado.

c. SHF (creada en 2002), a través del Programa Especial de Crédito y Subsidio a la Vivienda apoya con un subsidio que puede ser complemento del enganche para la adquisición de una vivienda, para quienes no cotizan en el IMSS o ISSSTE. Es limitada la oferta de créditos debido a que solo se destina a edificaciones de conjuntos habitacionales autorizados.

d. FOVISSSTE atiende solamente a trabajadores del Estado, el monto máximo es de 452 mil pesos (año 2004) un plazo hasta por 30 años con una tasa fija de interés entre el 4\% y $6 \%$ anual.

2. Créditos Hipotecarios primordialmente se destinan a viviendas media (un millón de pesos), residencial (dos millones de pesos) y residencial plus (dos millones en adelante) otorgados primordialmente por bancos y Sofoles.

a. Los criterios de elegibilidad son edad, ingresos mínimos, antigüedad en el trabajo, referencias crediticias y salud.

b. Las principales características que tienen estos créditos son la incidencia en el costo del financiamiento, la vida útil de la vivienda debe ser mayor a la del crédito, contar con todos los servicios básicos y tener uso residencial, el monto máximo del financiamiento varía entre de 60\% para planes de vivienda residencial plus hasta $95 \%$ en el programa Apoyo Infonavit.

c. El plazo es de 5 a 30 años y la tasa puede ser fija, variable, a tope o protegida y mixta, que implica un pago mensual. Se tiene adicionalmente en algunos casos bonificaciones, que pagar seguro de vida, seguro de daños, seguro de desempleo, realizar pagos anticipados, se cobran pagos iniciales, así como cobro de interés moratorio.

3. El Autofinanciamiento es un sistema de comercialización de bienes en el que las aportaciones mensuales de la adquisición de vivienda se aporta a un fideicomiso (SOFOLES, Sociedades Financieras de Objeto Limitado),en el que se financia la adquisición a un miembro del grupo de forma mensual seleccionado mediante diversos mecanismos. Requiere un pago inicial de entre el $1.5 \%$ y $2 \%$ del monto del financiamiento.

a. Una vez que se obtiene el financiamiento el inmueble se asegura contra daños y queda en garantía a favor del resto de las personas del fideicomiso. 
b. No requiere comprobar ingresos y pueden realizarse aportaciones anticipadas. Sin embargo, puede llegar a aportar por años sin tener el bien inmueble y pagar renta durante ese periodo (PROFECO, 2004:13-19).

\section{CARACTERÍSTICAS DE LA VIVIENDA}

Los datos estadísticos del INEGI para el año 1990 mencionan que en México se contaba con un total de $80^{\prime} 889,997$ habitantes en viviendas particulares habitados, para el año 200 se llega a 97'114,079, en el 2010 ya se superaban los 110 millones y para el 2015 el total llegó a 119'530,753 habitantes en viviendas particulares. La tasa de crecimiento de 1990 al año 2000 fue de $1.9 \%$ mientras que del año 2000 al 2010 y entre el 2010 y el 2015 se mantuvo en $1.4 \%$ (INEGI, 2015:1-2).

El 62\% de la población habita ciudades de más de 15,000 habitantes, lo que enfatiza el gran desarrollo de las ciudades en nuestro país (INEGI, 2015:2-5).

En el ámbito del empleo, el 50.3\% de la población entre 12 años y más trabajaba para el año 2015, mientras que para el año 2000 el 49.3\% y para el 2010 el 52.6\% lo hacía. El 11.1\% de los trabajadores se encuentra en el sector agropecuario, el $25.2 \%$ en el industrial y de la construcción y $62.1 \%$ en el sector de comercio y servicios. El $73.2 \%$ son trabajadores asalariados, $19.6 \%$ trabajan por cuenta propia y el resto son empleadores o trabajadores sin paga para el año 2015, de los cuales solamente el 64.5\% recibe prestaciones laborales (INEGI, 2015:85-89). Esto muestra las principales características económicas de la población y su poca capacidad adquisitiva de la mayoría de la población en organismos como el INFONAVIT y el FOVISSSTE.

En la figura 1 se observa la distribución por entidad federativa de los 31.9 millones de hogares que el INEGI define como la unidad formada por una o más personas, unidas o no por lazos de parentesco. 


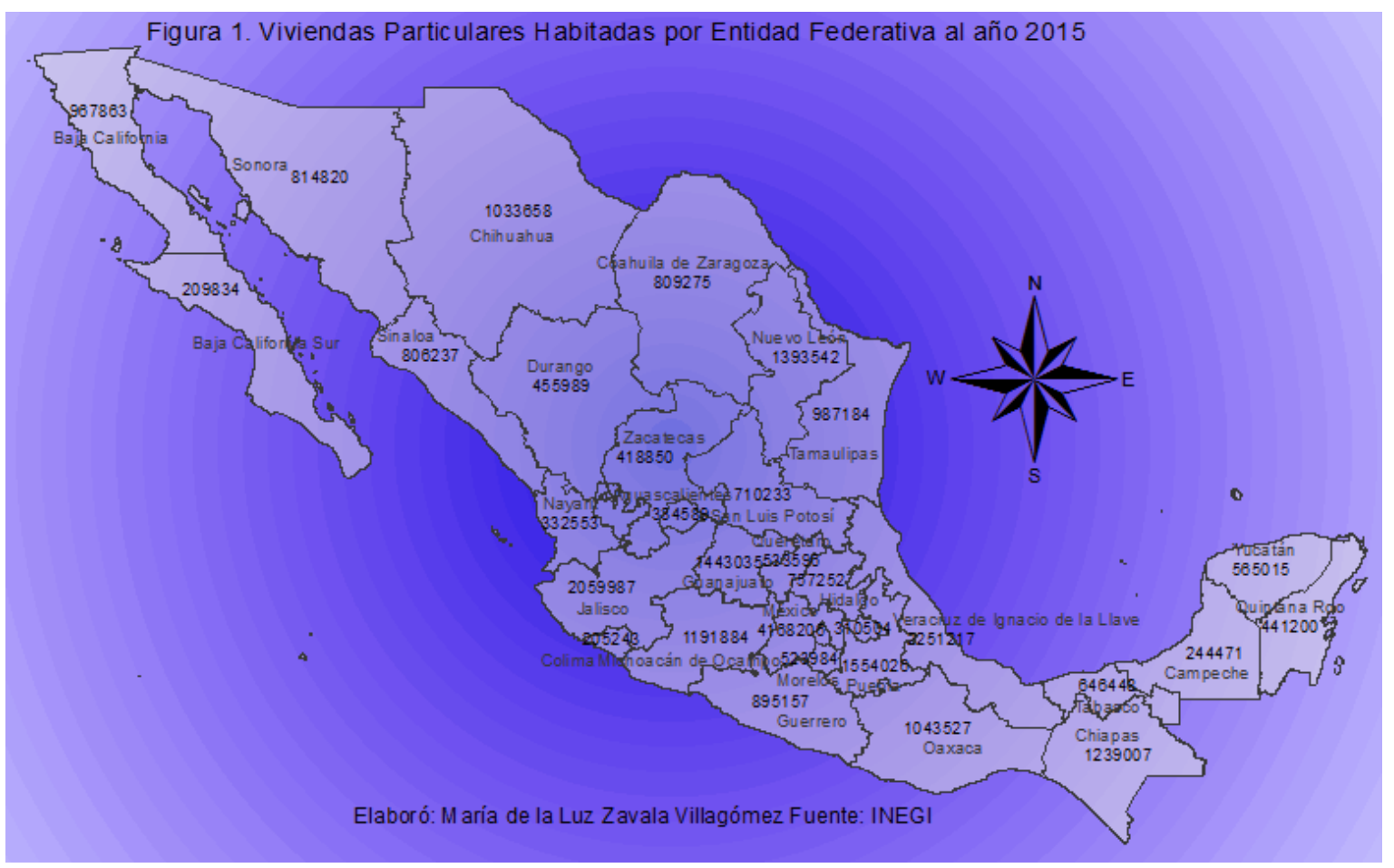

Las viviendas particulares habitadas por su parte el INEGI las define como las unidades de habitación predominante en nuestro país y brindan elementos determinantes para el estudio de las condiciones de vida de los ocupantes. Las viviendas particulares habitadas para el año de 1990 fue de 16'183,310, en el 2000 de 21'942,535, para el 2015 de 28'607,568 y en el 2015 la cifra alcanzó los 31'949,709 viviendas particulares habitadas.

El mayor porcentaje de viviendas particulares habitadas se encuentra en los estados de México con 4'168,206, Distrito Federal con 2'601,323, Veracruz con 2'251,217, Jalisco con 2'059,987 y Puebla con 1'554,026. El menor porcentaje de viviendas particulares habitadas se encuentra en los estados de Tlaxcala con 310,504, Campeche, Baja California Sur y Colima, datos al año 2015 del INEGI.

\section{TIPO DE VIVIENDA Y ESPACIOS CONSTRUÍDOS}

Las viviendas particulares habitadas crecen en proporción al crecimiento de la población y del número de viviendas, el mismo caso ocurre para las casas independientes y local no construido para habitación. En el caso de departamento en edificio y cuarto en vecindad el porcentaje que se tiene al año 2010 es de 3.53\%\%, para las demás clases de vivienda el porcentaje es igual o menor al 1\% (Gráfico 1). 


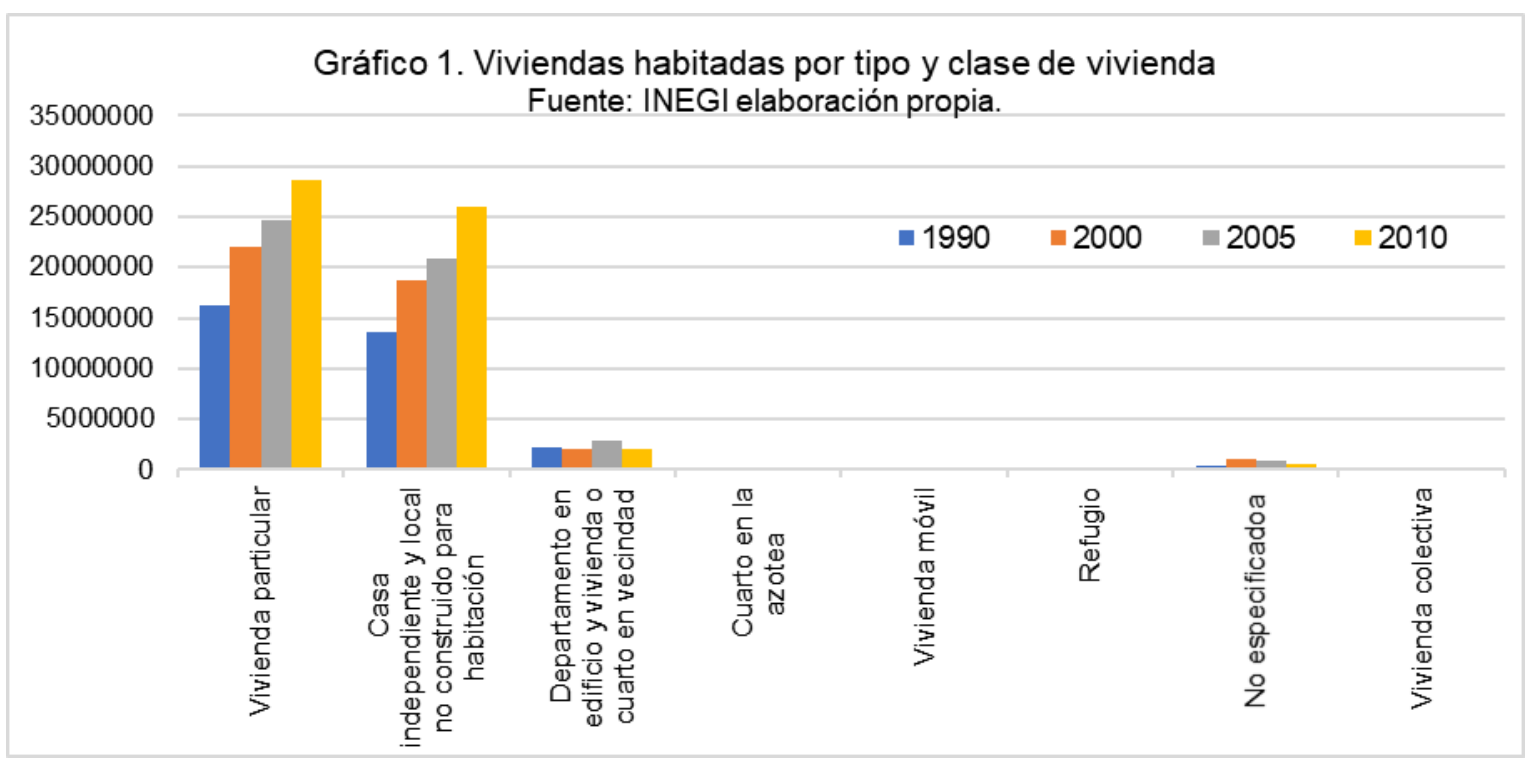

Las viviendas particulares habitadas por el número de cuartos que la integran, que predomina es cuatro con $23.53 \%$ junto con tres cuartos con un porcentaje de $23.31 \%$, en el caso de dos cuartos el porcentaje se reduce a $16.95 \%$ y para 5 cuartos de $15.16 \%$ para el año 2010 (Gráfico 2), es importante destacar que los cuartos considerados por el INEGI son espacios construidos, sin ser necesariamente dormitorios como se analiza más adelante.

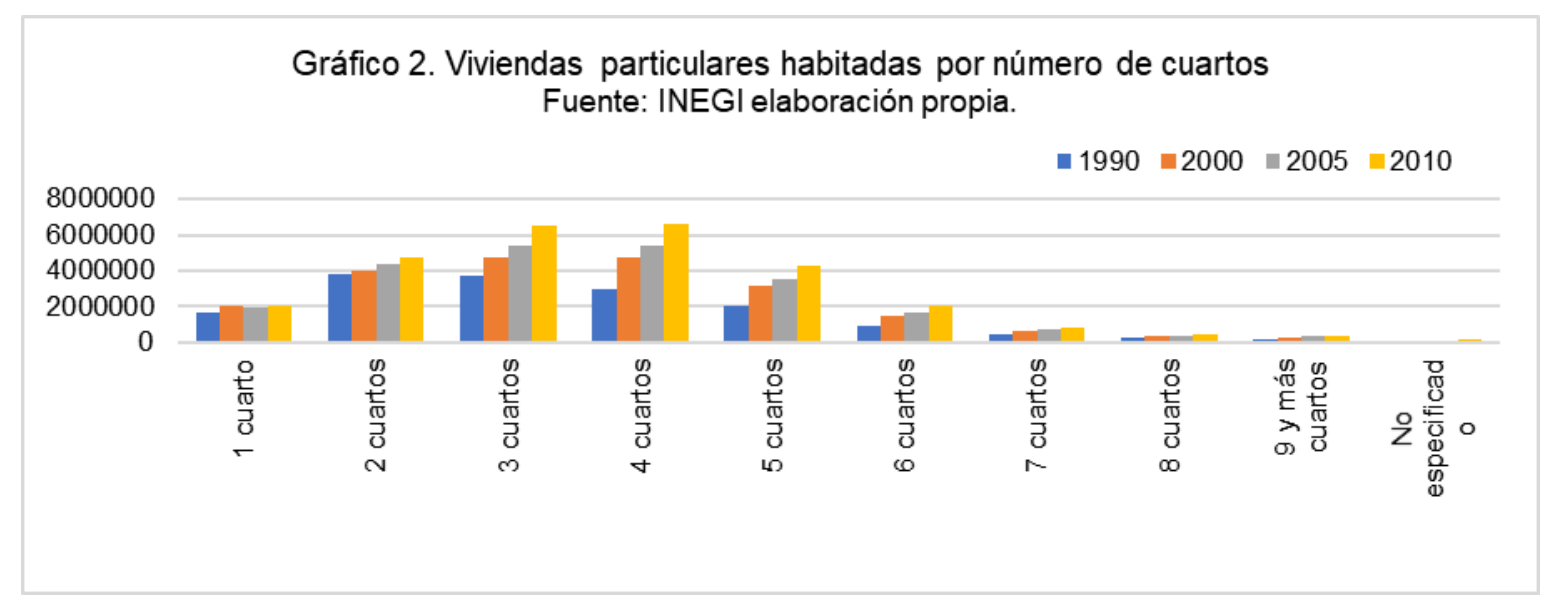

En la Figura 4 podemos observar que la mayor cantidad de viviendas particulares habitadas con un cuarto se encuentran al sur del país, mientras que en menor porcentaje los estados que se encuentran al centro y norte del país. 


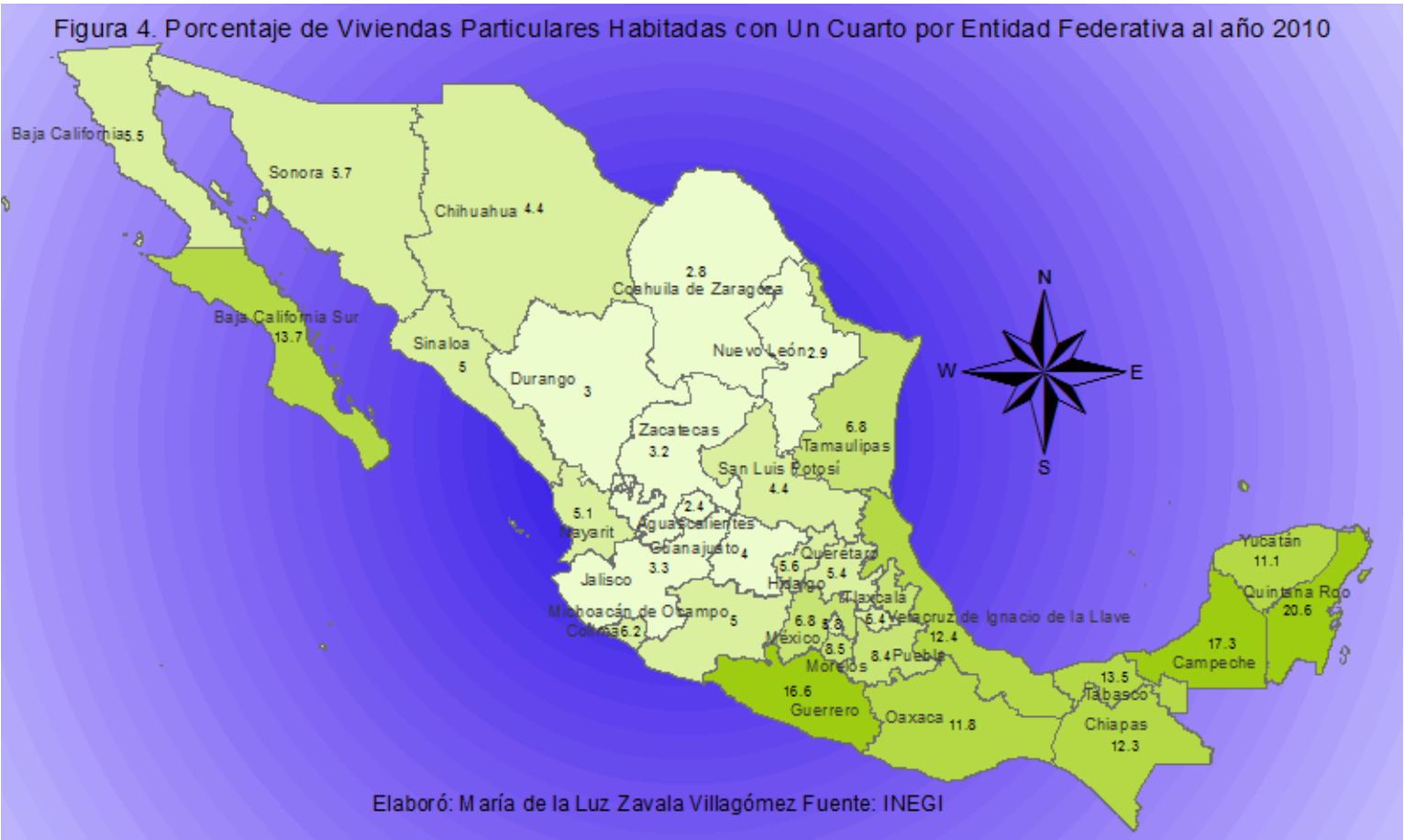

Las viviendas particulares habitadas con dos cuartos tienen un mayor porcentaje en los estados de Guerrero, Oaxaca y Chiapas, mientras los de menor porcentaje al norte y centro del país (Figura 5).

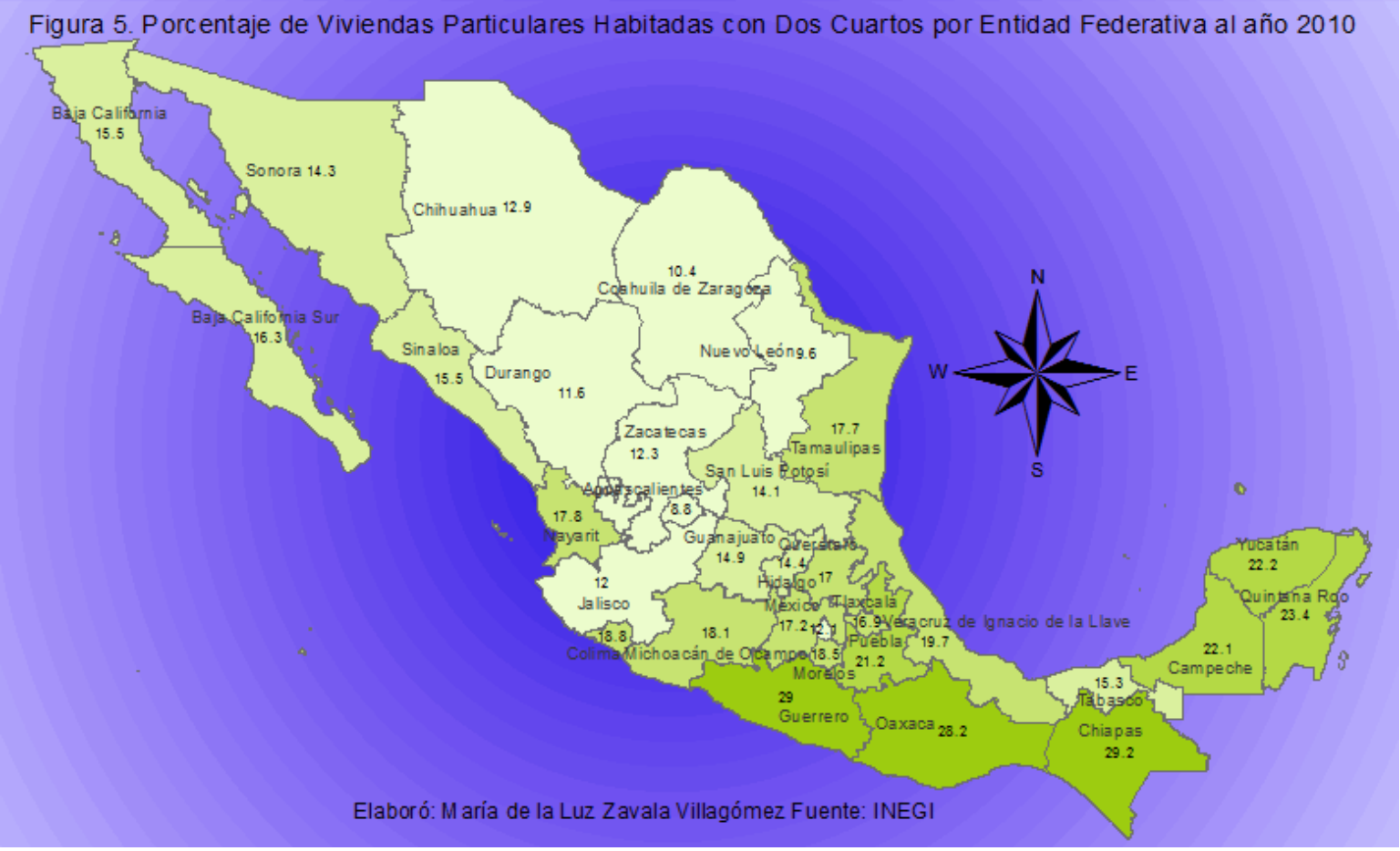

Las viviendas particulares habitadas en nuestro país cuentan en su mayoría por uno y dos dormitorios, seguidas de las de 3 dormitorios (Gráfico 3). 


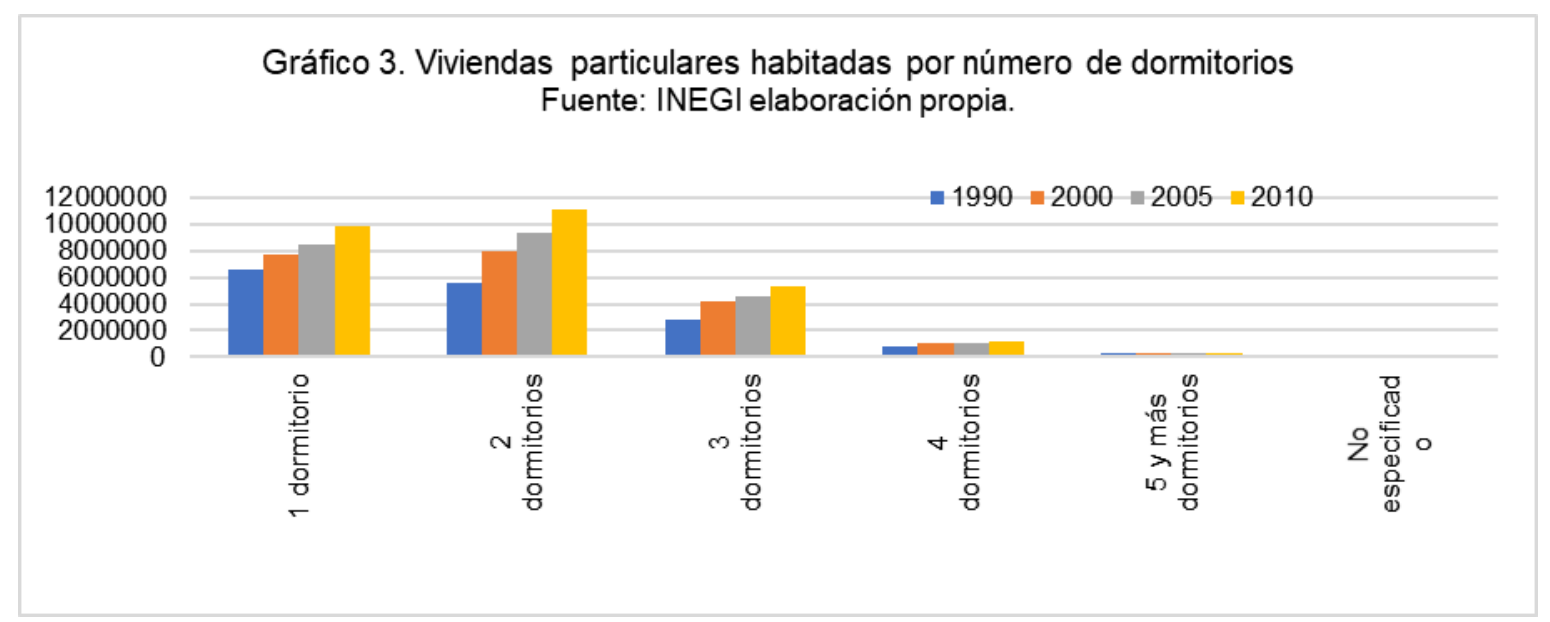

Los bienes y servicios con los que cuentan las viviendas particulares habitadas al año 2010 acorde a datos estadísticos del INEGI se resumen a continuación. Para el caso de viviendas con recubrimientos en pisos los estados de Chihuahua, Hidalgo, Tlaxcala y Puebla cuentan con los menores porcentajes con un rango del 805 al 84\%, llegando a valores cercanos al 100\% en Baja California Norte y Sur, Durango, Zacatecas, entre otros.

\section{RÉGIMEN DE PROPIEDAD Y DE TENÊNCIA}

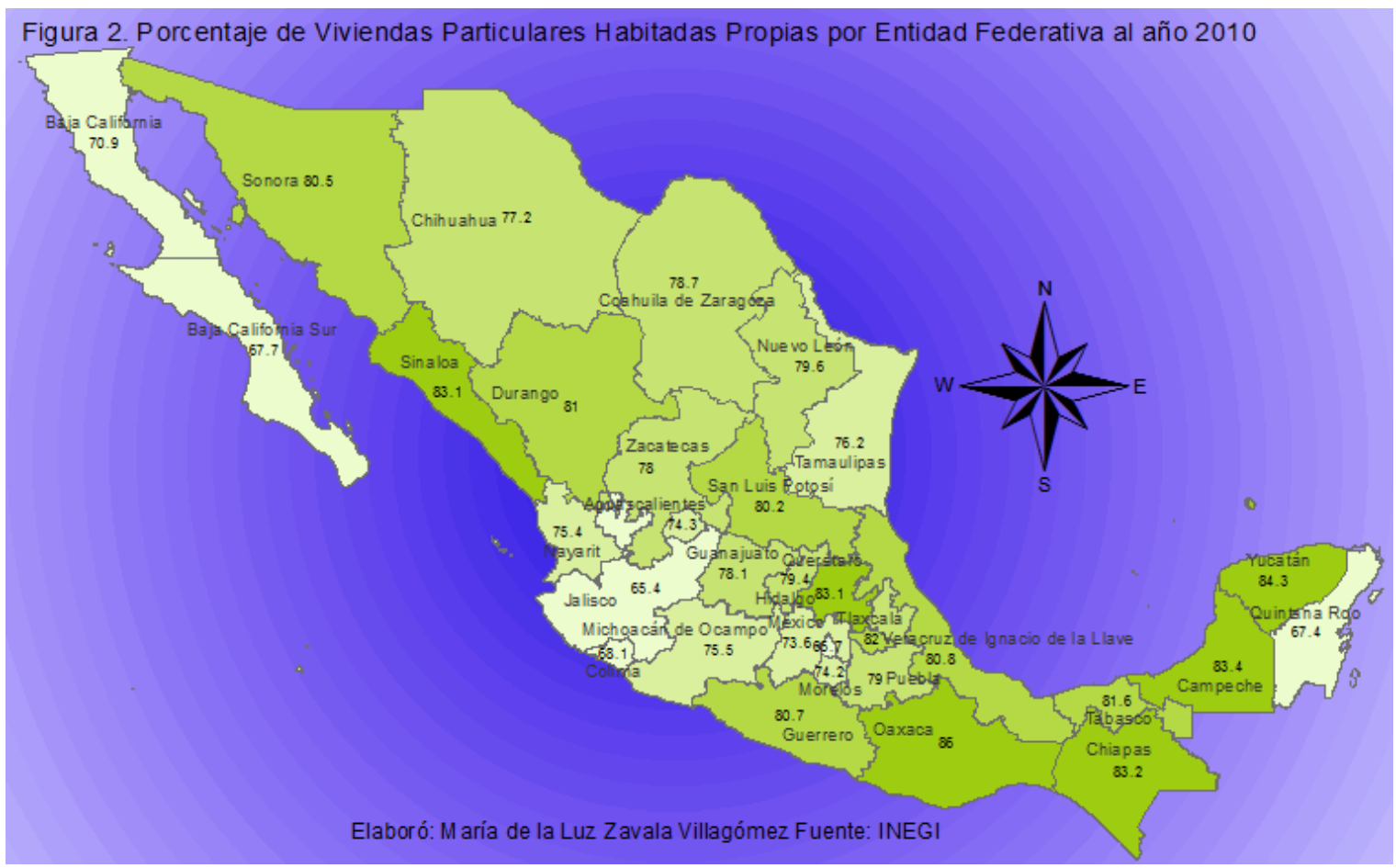

El régimen de propiedad en el caso de las viviendas particulares habitadas propias, los mayores porcentajes se encuentran en los estados de Oaxaca con 86\%, Yucatán con 84.3\%, Campeche con $83.4 \%$, Chiapas con $83.2 \%$, Hidalgo y Sinaloa con $83.1 \%$, mientras que los 
estados con mayor porcentaje de viviendas particulares habitadas propias son Colima con 68.1\%, Quintana Roo con 67.4\%, Distrito Federal con 66.7\% y Jalisco con 65.4\% al año 2010 datos del INEGI (Figura 2).

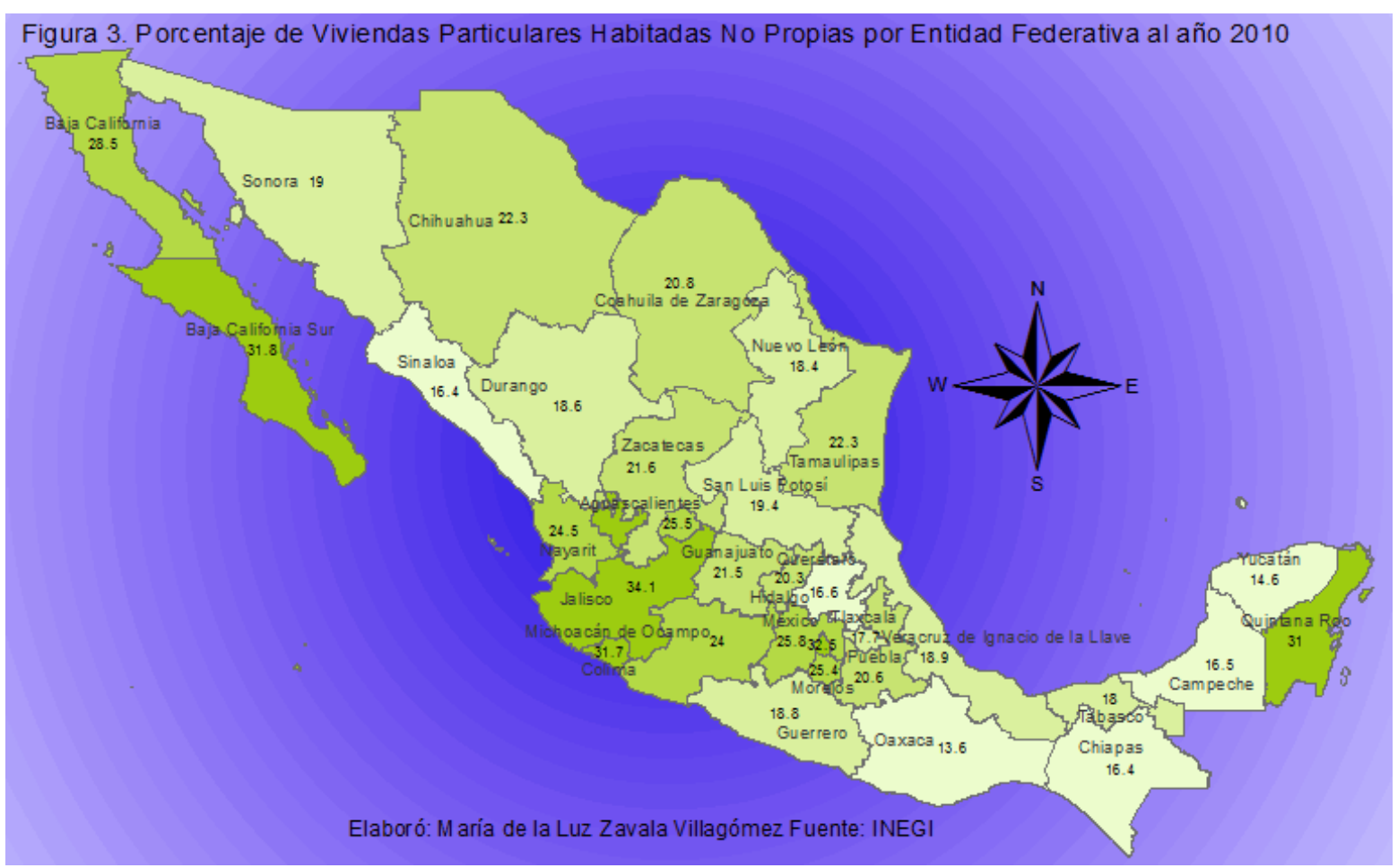

A contrapar con el análisis anterior, las viviendas particulares habitadas no propias en mayor porcentaje se encuentran en los estados de Jalisco con 34.1\%, Distrito Federal con 32.5\%, Quintana Roo con 31\%, Baja California Sur con 31.8\%, seguida por Colima con 31.7\%, mientras que los estados con un porcentaje bajo son Oaxaca con 13.6\%, Yucatán con 14.6\%, Chiapas y Sinaloa con 16.4\%, Campeche con 16.5 e Hidalgo con 16.6\% (Figura 3).

\section{CARACTERÍSTICAS CONSTRUCTIVAS Y SERVICIOS}

Las viviendas particulares habitadas con materiales resistentes en techos para el año 2010 muestran los menores porcentajes en los estados de Tamaulipas, Coahuila, Chihuahua, Yucatán, Baja California Sur, Hidalgo, Tlaxcala y Puebla por debajo del 55\%, Ilegando a alcanzar el 94.9\% de cobertura en el estado de Baja California.

Las viviendas particulares habitadas con materiales resistentes en paredes cuenta con un rango del 63\% en el estado de Hidalgo llegando al 99.6\% para el estado de Quintana Roo el año 2010 acorde a datos del INEGI. 
Estos datos nos muestran que en cuanto a los materiales de construcción en la vivienda en nuestro país aún se cuenta con una deficiencia muy importante.

La disponibilidad de drenaje en las viviendas particulares habitadas tiene menor representatividad en los estados del sur que llega a $71.7 \%$ para el estado de Guerrero, mientras que los estados con mayor cobertura son Distrito Federal con 99.2\%, seguido por Colima, Aguascalientes y Nuevo León.

\section{ANÁLISIS DE FINANCIAMIENTO PARA LA VIVIENDA}

Las tres financiadoras principales en nuestro país son INFONAVIT, FOVISSSTE y entidades financieras (Incluye: Banca, Sofoles, Banobras y Banjercito), dejando un mínimo de porcentaje a las demás financiadoras como lo son SHF, FONHAPO y CONAVI (Gráfico 4).

No existe un incremento constante en los montos de inversión en financiamiento para viviendas otorgados por cada una de las instituciones, en el caso de los organismos gubernamentales específicamente, se observa una tendencia clara a la disminución de dichos montos que se da a partir del año 2010, aunque en el año 2005 tiene una importante recuperación.

Un detalle adicional que podemos observar es el poco incremento que los montos de inversión en financiamiento para la vivienda de organismos gubernamentales en los últimos años y, en contra par, se observa que las entidades financieras si se está logrando, lo que indica que los créditos otorgados por las instituciones gubernamentales no son suficientes (Gráfico 4).

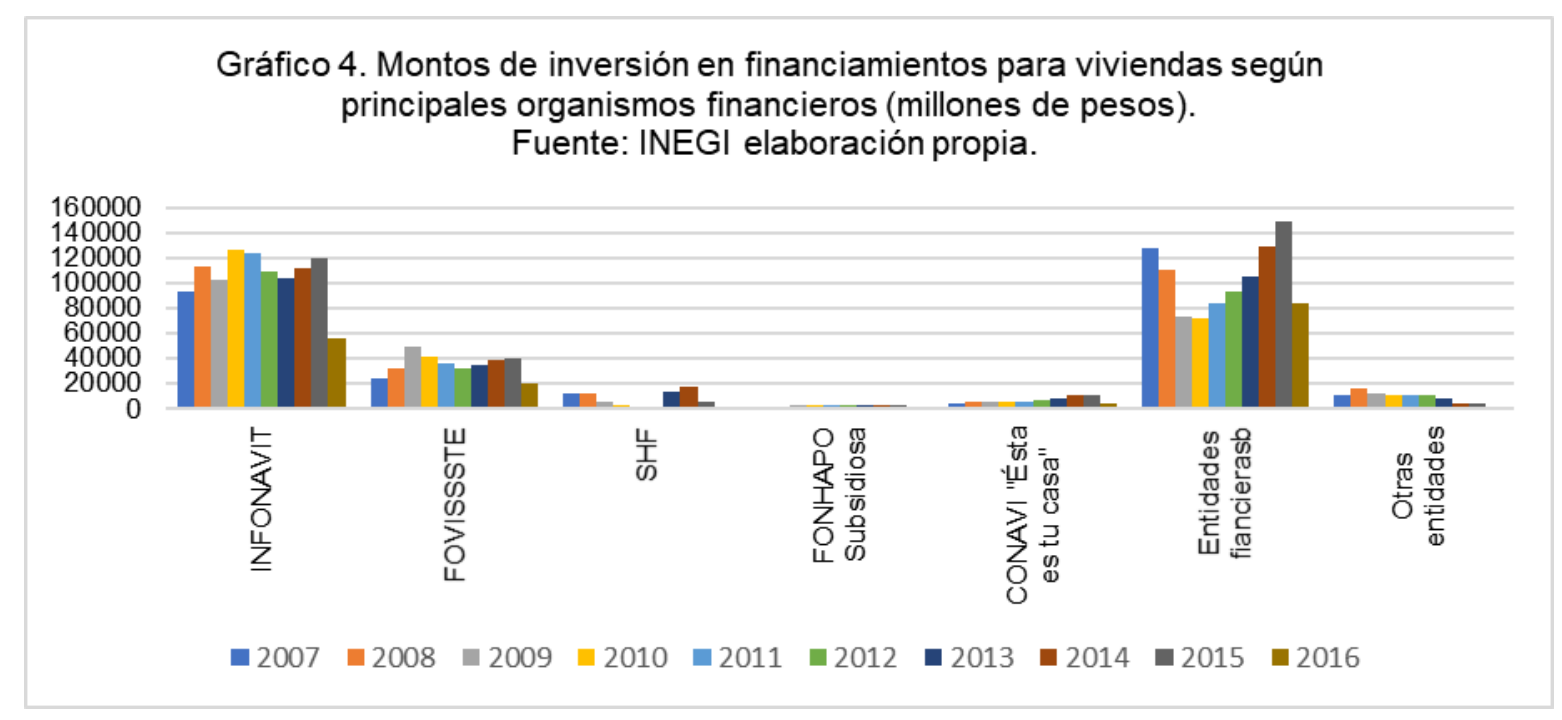


En el caso del INFONAVIT en los últimos años ha sido la mayor financiadora para vivienda pese a que los montos de inversión de financiamiento han disminuido, se tiene un importante incremento en el número de financiamientos para vivienda entre los años 2007 al 2013, teniendo una disminución del 17\% con respecto al año 2014 alcanzando un total de 556,000 financiamientos que en el año 2016 se redujeron a un total de 140,080 financiamientos que representó una disminución del 67\% (Gráfico 5).

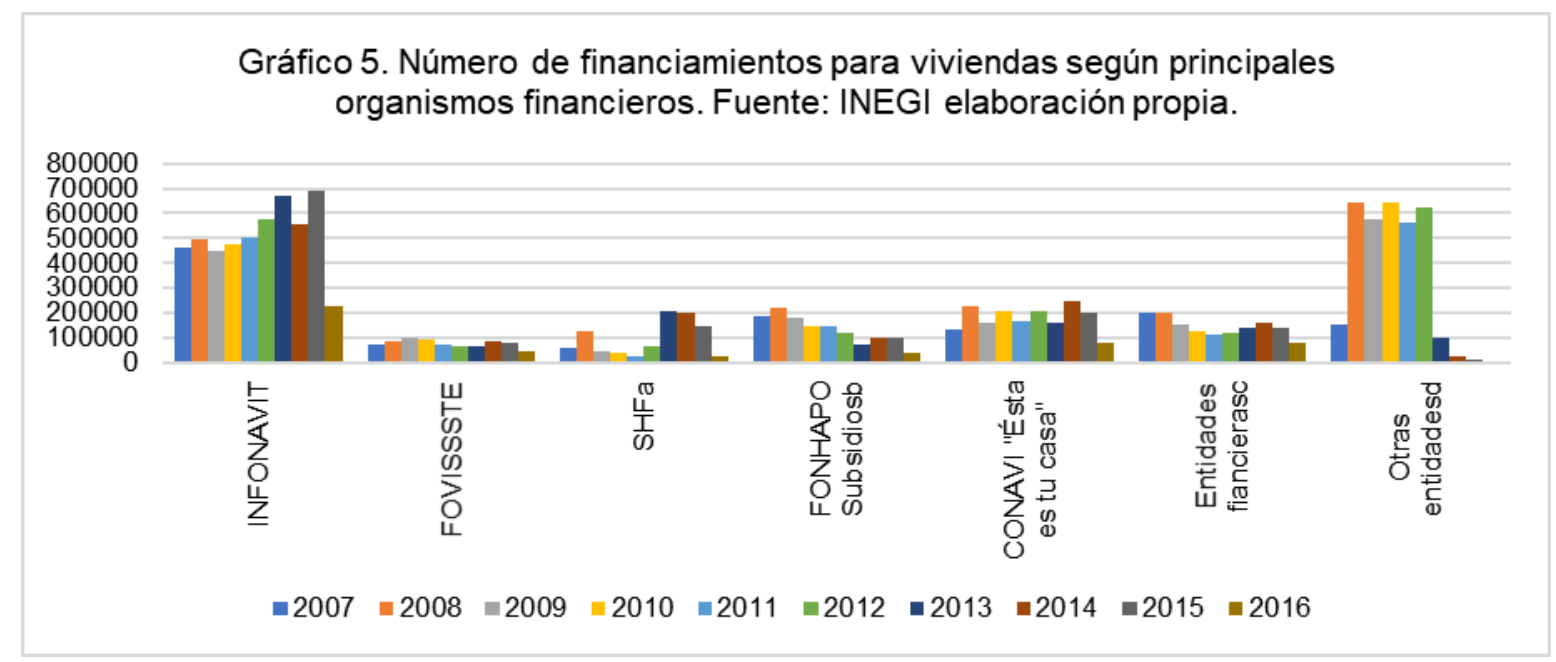

El número de financiamientos para viviendas en el lapso del año 2008 al año 2012 en las otras entidades financieras es casi constante, sin embargo en el año 2013 reduce más del 75\% con respecto al precedente año, para culminar en el año 2016 con solamente el 2\% con respecto al 2012 con un total de 2,000 financiamientos (Gráfico 5).

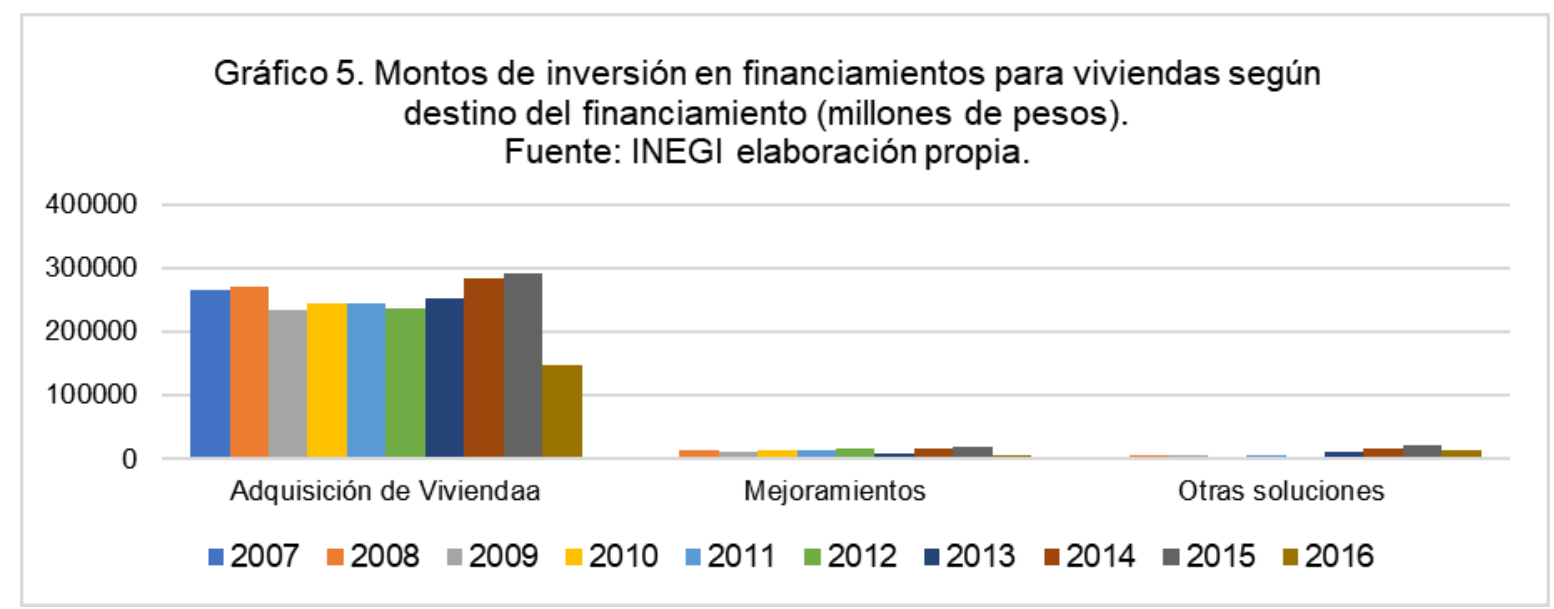

Se puede observar que en el año 2016 se tuvo un decremento en los montos de inversión de financiamiento para viviendas que 50.6\%, lo que significa una elevada disminución en el número y monto de los financiamientos otorgados para la vivienda (Gráfico 5). 
El número de financiamiento para viviendas según destino del financiamiento a partir del año 2008 ha tenido una clara tendencia a su disminución, llegando al año 2015 a un total de 782,000 financiamientos para la adquisición de vivienda y un total de 568,000 financiamientos para mejoramiento de la vivienda, teniendo la peor disminución en el número de financiamientos en el año 2016 con un total de 360,000 financiamientos para la adquisición de vivienda y de 130,000 financiamientos para mejoramiento al mismo año (Gráfico 6).

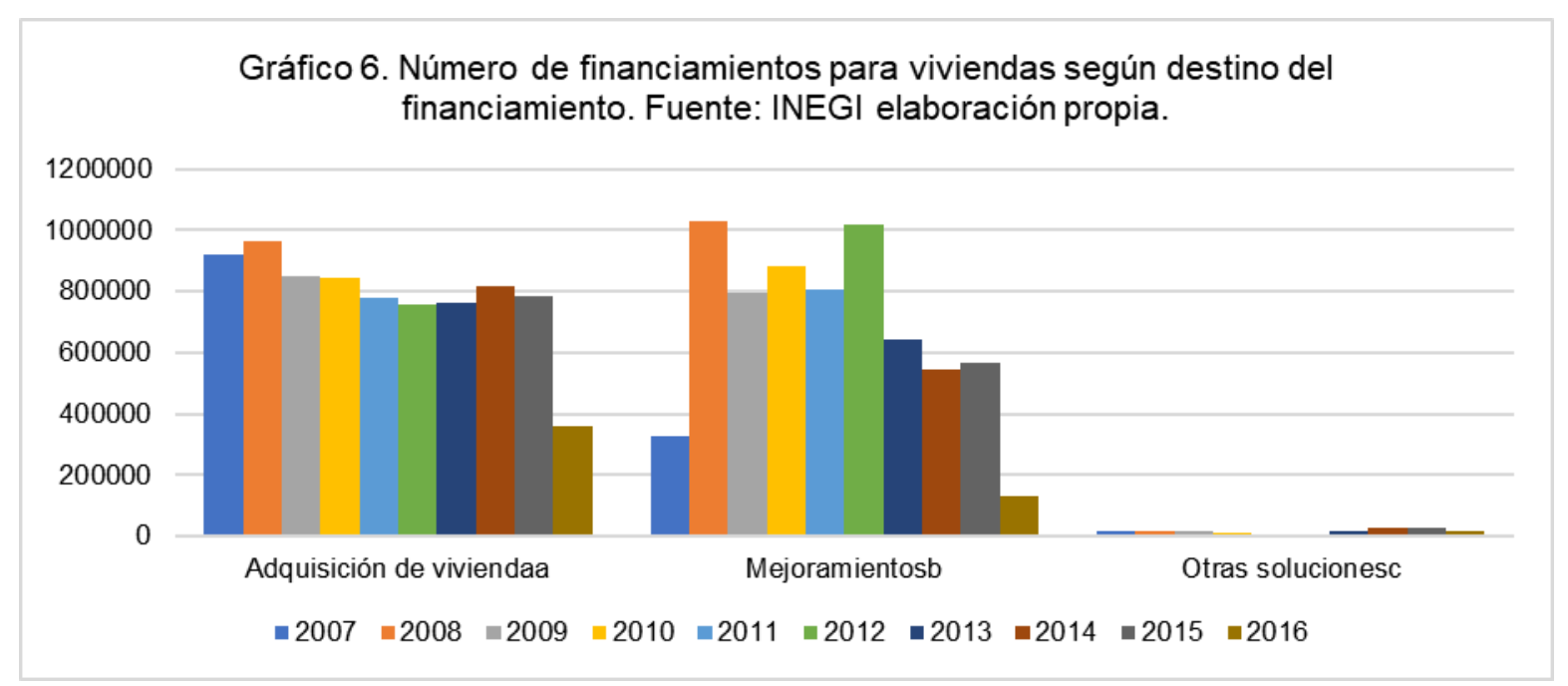

Esto represento un aproximado de más del 55\% de reducción en los financiamientos para la adquisición de vivienda y una reducción del $77 \%$ de financiamiento para mejoramiento de la vivienda.

\section{CONCLUSIONES}

En México las reformas neoliberales del Estado no han permitido que las políticas sociales de vivienda puedan focalizarse a los grupos más vulnerables. Es necesario que el Estado gestione los recursos jurídicos y económicos necesarios para que fomente el desarrollo de vivienda digna, con materiales de calidad, con eficiencia energética y uso de energías renovables, que conserve su entorno y emplee lo mínimo de recursos. Del mismo modo, el Estado debe revisar y modificar los argumentos legales para que sean esos grupos sociales los que reciban los subsidios y apoyos referentes a la adquisición y mejoramiento de la vivienda.

Las intervenciones del estado en la producción de vivienda lograron una muy importante institucionalización y canalización de recursos en la conformación de instituciones de financiamiento y promoción de la vivienda (Pírez, 2014:487). Sin embargo, la demanda actual de vivienda ha sobrepasado las capacidades de dichos organismos. 
La escases y mala calidad de la vivienda en el país, sin embargo, no se soluciona desde los planes y programas específicos para la vivienda. Es necesario además que se tengan las condiciones laborales para que los trabajadores del área rural y urbana sean capaces económicamente de tener los recursos y prestaciones que los acrediten para una vivienda acorde a sus necesidades, cerca de su área de trabajo, con dotación de infraestructura y servicios de calidad.

Aunque la cantidad de viviendas ha crecido significativamente en nuestro país en los últimos años, aún existen deficiencias importantes en la calidad de la vivienda, como lo es el caso de pisos, muros y techos de materiales de calidad y acorde a las necesidades del clima, así como servicios básicos como lo es el drenaje.

Acorde a los datos analizados en cuanto a régimen de propiedad y de tenencia, se observa que existe un elevado porcentaje de personas que habita en viviendas no propias, en alguno casos los estados con mayor número de viviendas particulares habitadas, que muestra que en dichos estados no se ha cubierto la demanda de vivienda y, que por otro lado, se recurre al arrendamiento para cubrir la necesidad de habitación.

En el ámbito financiero se observa que a partir del año 2011 se han llevado a cabo más créditos en las entidades financieras, lo que enfatiza que las instituciones generadas para tal fin no proporcionan a los trabajadores créditos acordes a sus necesidades.

Adicionalmente, se observa que en la vivienda mínimamente se financia para remodelaciones, ampliaciones o mejoramiento con crédito. Esto habla por un lado que posiblemente en México no se tenga el hábito de mejora de la vivienda o por el contrario, sea constante y no requiera de montos de inversión elevados para poder llevarlo a cabo, lo que hace innecesario el financiamiento.

Otro punto importante a destacar es la reducción significativa que se tuvo en el número de financiamientos para la vivienda entre el año 2015 y 2016 que paso de 690,000 créditos a tan sólo 230,000, que representa una tercera parte. Similar ocurrió en el mismo periodo en las entidades financieras en las que los créditos se redujeron a la mitad. Esto muestra la poca capacidad que se tiene en el ámbito laboral para gestionar adecuadamente los recursos de los trabajadores para acreditar ser sujeto de crédito. 


\section{BIBLIOGRAFÍA}

ALAVEDRA, P., Domínguez, J., Gonzalo, E., \& Serra, J. (1997). La construcción sostenible: el estado de la cuestión. Informes de la Construcción, España, a.49, n. 451, p. 41-47.

BBVA Bancomer (2009). El financiamiento del mercado de vivienda en México. Crédito Empresarial y Crédito Individual. Antecedentes y perspectivas. Consultado el 05-08-2017 desde: http://www.cmic.org.mx/comisiones/Sectoriales/vivienda/memoriasRNV09/Panel3/IsidoroSanc hez.pdf

CONNOLLY, P. (1997). El financiamiento de vivienda en México. Consultado el 10-08-2017 desde: http://infonavit.janium.net/janium/UAM/Documentos/19752.pdf

de Diputados, C. (1917) Constitución Política de los Estados Unidos Mexicanos. México: Cámara de diputados.

ESQUIVEL H. M. T. (2006) Política habitacional y calidad de vida: impacto de los nuevos desarrollos habitacionales. En: Borjas Benavente, A., \& Escobedo, M. B. La vivienda en México: construyendo análisis y propuestas. México: Centro de Estudios Sociales y de Opinión Pública/Cámara de Diputados-LIX Legislatura.

GARCÍA P., C. M. y García E., S. (S/F) Urbanismo y vivienda en México.

INEGI (Instituto Nacional de Estadística y Geografía) consultado el 13-12-2016 desde: http://www.inegi.org.mx/geo/contenidos/urbana/default.aspx.

http://www.inegi.org.mx/est/contenidos/proyectos/ccpv/default.aspx

Isunza Vizuet, G. (2010). Efectos urbano-ambientales de la política de vivienda en la Ciudad de México. Espiral, Guadalajara, a. 17, n. 49, p. 129-159.

NAREDO, J. M. (2003). Mercado de suelo y plusvalías. Página Abierta, p. 142-143, nov./dic.

ONU HABITAT (2001). Carta Mundial por el Derecho a la Ciudad. "Patrimonio": Economía Cultural Y Educación Para La Paz. Mec-Edupaz, n.3, p. 91-106.

PÍREZ, P. (2014) La mercantilización de la urbanización, a propósito de los "conjuntos urbanos" en México. En Estudios Demográficos y Urbanos, Vol. 29, Núm. 3(87), p. 481-512.

PROCURADURÍA FEDERAL DEL CONSUMIDOR (PROFECO) (2004) Financiamiento Inmobiliario. Consultado el 12-08-2017 desde: https://www.profeco.gob.mx/revista/publicaciones/adelantos_04/inmobiliarias_mzo04.pdf.

SAUCEDO C., A (2012) El mercado mexicano de créditos hipotecarios como modelo de oligopolio mixto. Tesis. Asesor Vitaliy V. Kalashnikov. UANL. México. Consultado el 16-08-2017 desde: http://eprints.uanl.mx/6508/1/El\%20Mercado\%20Mexicano\%20de\%20Cr\%C3\%A9ditos\%20Hip otecarios\%20como\%20Modelo\%20de\%20Oligopolio\%20Mixto.pdf.

SCHTEINGART, M. y García, B. (2006) Nuevas políticas de vivienda en México. Nuevas relaciones entre el sector público y privado y retos para el futuro. En: Borjas Benavente, A., \& Escobedo, M. 
B. La vivienda en México: construyendo análisis y propuestas. México: Centro de Estudios Sociales y de Opinión Pública/Cámara de Diputados-LIX Legislatura.

Trabalho enviado em 03 de janeiro de 2018.

Aceito em 05 de fevereiro de 2018. 